\title{
Alfabetización y cobertura escolar en Hispanoamérica. La primera expansión educativa costarricense $(1750-1830)^{*}$
}

\author{
Iván Molina Jiménez
}

\begin{abstract}
Este artículo plantea que entre 1750 y 1830 Costa Rica experimentó una primera expansión escolar, impulsada sucesivamente por las Reformas Borbónicas, por la Constitución de Cádiz (I8I2) y por el nuevo orden político surgido tras la independencia de España (182I). Como resultado de este proceso, la alfabetización se extendió, especialmente entre los hijos varones de pequeños y medianos productores urbanos y rurales. A partir de la década de 1830, sin embargo, el país registró un retroceso en la alfabetización, producto de los procesos de colonización agrícola que alejaban a la población de la infraestructura educativa existente, del rezago de la inversión escolar en relación con el crecimiento demográfico y de la reducción en el número de municipalidades, que eran las que tenían a su cargo la educación primaria.
\end{abstract}

PALABRAS CLAVE: educación, alfabetización, Reformas Borbónicas, Constitución de Cádiz, Costa Rica

\section{Literacy and School Coverage in Latin America.The First Costa Rican Educational Expansion} (1750-I830)

This article argues that from 1750 to 1830 Costa Rica experienced the first expansion of the school system encouraged by the Borbonic Reforms, the Constitution of Cadiz (I8I2) and the new political order after independence from Spain (I82I). Literacy mainly expanded between small and medium producers male children from urban and rural settings. However, starting in the 1830's, Costa Rica experienced a decline in literacy product of three processes. First, the colonization of new land separated the immigrants from existing educative infrastructure. Secondly, the gap created by the lack of investment in education and its relation with demographic growth. Thirdly, the reduction of the amount of municipalities created on an expanding country (municipalities were in charge of the administration of elementary schools).

KEYWORDS: education, literacy, Bourbon Reforms, Cadiz Constitution, Costa Rica

Iván Molina Jiménez: Escuela de Historia, Universidad de Costa Rica, San José, Costa Rica ivan.molina@ucr.ac.cr

Desacatos, núm. 37, septiembre-diciembre 2011, pp. 125-144

Recepción: 20 de mayo de 2009 / Aceptación: 8 de julio de 2009

\footnotetext{
* La presente investigación se llevó a cabo en el Centro de Investigación en Identidad y Cultura Latinoamericanas (CIICLA) de la Universidad de Costa Rica.
} 
$\mathrm{E}$ 1 viajero inglés John Hale, quien estuvo de visita en Costa Rica en 1825, destacó que, entre algunos de sus habitantes había un "gran deseo de poseer una imprenta y de establecer un periódico. En la actualidad se ven obligados a enviar a San Salvador (un viaje de tres o cuatro semanas) aun sus leyes para que allí las impriman" (Hale, 1982: 28). Aunque la introducción de la imprenta debió esperar hasta 1830 (Vega, 1995: 1950), la observación de Hale sugiere que, en una época tan temprana, existía ya un claro interés - de la sociedad civil y del Estado- por producir materiales impresos localmente. ¿Había una población lo suficientemente alfabetizada para responder a esta oferta cultural?

El problema al que se refiere tal pregunta es el objeto del presente artículo, cuyo propósito es analizar la influencia que las Reformas Borbónicas, la Constitución de Cádiz (1812) y el nuevo orden surgido tras la independencia de España (1821) tuvieron en la temprana alfabetización de la población experimentados por los estudios sobre este tema en Europa y Estados Unidos en las últimas décadas (Graff, 2003: 123-131), poco es lo que se ha investigado al respecto para la Hispanoamérica colonial. La mayoría de los estudios existentes sobre la educación entre finales del siglo XVIII e inicios del XIX se concentran en considerar las políticas del caso (Newland, 1991a; 1991b: 336-337), pero sin examinar cómo afectaron los niveles de alfabetismo. Una de las contribuciones recientes más valiosas para Centroamérica, la de Sajid Herrera sobre las experiencias de San Salvador y Sonsonate entre 1750 y 1808 , comparte la tendencia indicada, ya que evalúa el impacto de las medidas impulsadas por los Borbones con base principalmente en el número de escuelas y de alumnos (Herrera, 2007: 17-45).

En lo tocante a Costa Rica la situación no es muy distinta, ya que las únicas tres investigaciones que exploran el periodo anterior a 1850 (González Flores, 1978: 17-173; Muñoz, 2002: 3-89; Quesada, 2007: 95167) basan sus conclusiones en información similar a la utilizada por Herrera. En contraste, el presente

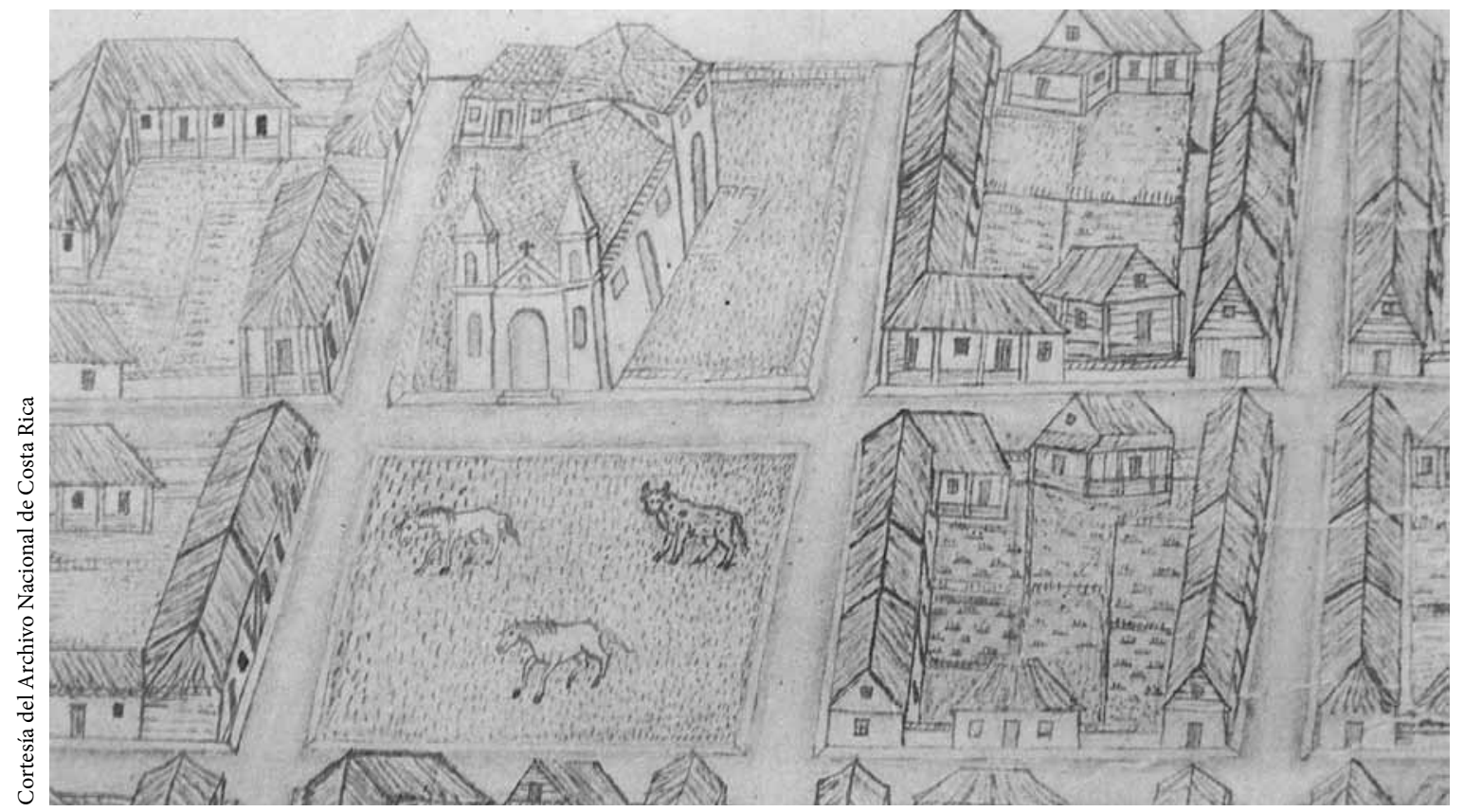

Cartago a inicios del siglo XVII, "Álbum de Figueroa". 
Mapa 1. Costa Rica: poblaciones, puertos y caminos (1750-1830)

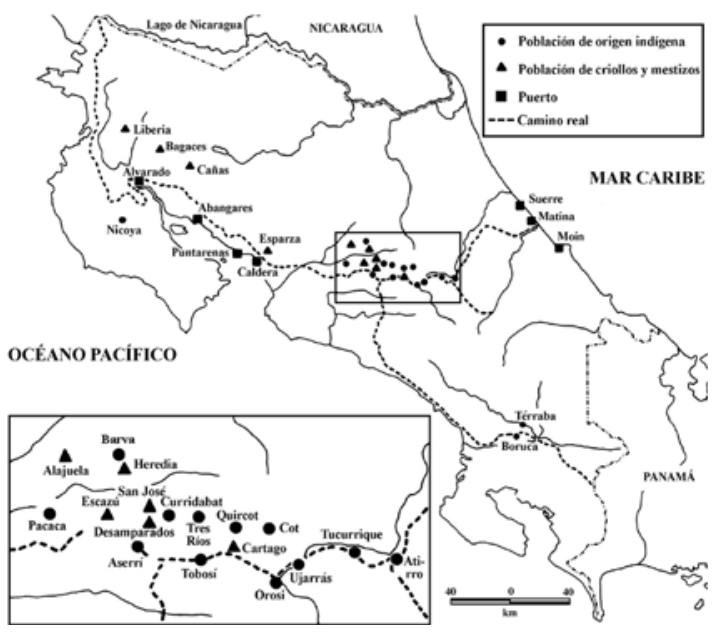

Fuente: Molina (1991).

artículo apela a otra fuente: a partir de una revisión exhaustiva de las dispensas matrimoniales tramitadas entre 1801 y 1850 , se elaboró una base de datos de 2372 personas, 491 mujeres y 1881 varones, de los cuales se conoce la vecindad, la edad, si sabían firmar y, en algunos casos, la ocupación. Una vez determinado el año de nacimiento, y bajo el supuesto de que la firma es un indicador aproximado de alfabetización, es posible explorar la etapa inicial en que la sociedad costarricense aprendió a leer y escribir.

Los alcances y limitaciones de la metodología y las fuentes empleadas serán discutidos más adelante, por ahora conviene indicar que el artículo ha sido dividido en tres secciones principales. En las dos primeras se reconsidera la información disponible acerca de la creación de escuelas en el periodo colonial y la relación entre la expansión del número de estos establecimientos y las políticas educativas impulsadas por las Reformas Borbónicas, por la Constitución de Cádiz y por el incipiente Estado costarricense. En la tercera, se analiza el proceso de alfabetización a partir de la base de datos ya señalada, según género, vecindad, ocupación y periodo de nacimiento.

Dado que Costa Rica es un país que desde inicios del siglo xx empezó a ser ampliamente reconocido por sus logros educativos (Pan American Union, 1928: 1229), un estudio de la etapa en que se formó su sistema escolar resulta esencial para comprender cuáles fueron sus fundamentos. En este sentido, la selección del periodo 1750-1830 no sólo responde al interés por examinar indicadores aproximados de alfabetización antes y después de las Reformas Borbónicas, la Constitución de Cádiz y la independencia, sino a la preocupación por evaluar el impacto que el crecimiento económico y demográfico de finales del siglo xvin y la posterior intensificación de la colonización agrícola campesina tuvieron sobre la asistencia a la escuela (Molina, 1991: 48-55, 285-294).

\section{REFORMAS BORBÓNICASY ESCUELAS}

La Costa Rica colonial fue una provincia marginal del imperio español en América que experimentó dos estructuraciones básicas: en los siglos XVI y XVII, los españoles, asentados principalmente en Cartago (capital colonial), procuraron construir una sociero, y de los esclavos negros después; pero tal intento fracasó por la baja en la población aborigen y la ausencia de un producto de exportación viable que permitiera financiar la importación creciente de esclavos (Quirós, 1990: 231-290; Cáceres, 2000: 69-80, 118). En tales circunstancias, el periodo posterior a 1700 fue escenario de la expansión de la producción agropecuaria campesina (Fonseca, Alvarenga y Solórzano, 2001: 81-193), lo que supuso la paulatina ocupación del oeste del Valle Central, un área de unos $3200 \mathrm{~km}^{2}$ que corresponde a $6.4 \%$ del actual territorio costarricense (Hernández, 1985: 176).

Colonizado por productores libres, mayoritariamente mestizos, el occidente del valle fue el asiento de las poblaciones de Heredia, San José y Alajuela (véase mapa 1), en las que se concentraron los principales comerciantes de la época y una artesanía más especializada. Estos mercaderes, gracias a su posición dominante en el comercio exterior, establecieron una relación de intercambio desigual 
- "comprar barato y vender caro" - con los productores directos agrícolas y artesanales (Molina, 1991: 153-162). Hacia 1801, Costa Rica tenía entre 40000 y 50000 habitantes, más de $80 \%$ de los cuales residían en el Valle Central. Étnicamente, los mestizos constituían $60 \%$, los blancos $8 \%$, los indígenas $14 \%$, los mulatos, zambos y pardos $17 \%$, y los negros el 1\% restante (Thiel, 1977: 20-21; Pérez, 1988: 1-13).

En la mayor parte del periodo comprendido entre la década de 1580 y finales del siglo XVII, prácticamente no hubo escuelas en Costa Rica (véase cuadro 1). El único establecimiento conocido fue el que atendió entre 1583-1588 y 1623 el presbítero Diego de Aguilar, sacristán mayor de la iglesia parroquial. La ausencia de locales escolares obedeció en mucho a la escasa población de Cartago (apenas 320 personas entre blancos, negros, mulatos y mestizos en 1611) y a la dispersión de sus vecinos por los campos, por lo que era difícil lograr una matrícula suficiente para financiar un plantel formal. En tales circunstancias, las familias más pudientes optaron por contratar la instrucción de sus hijos con tutores particulares (Thiel, 1977: 64; González Flores, 1978: 40-41).
El ascenso de los Borbones en España, a comienzos del siglo xvirI, fue el punto de partida de un conjunto de reformas orientadas a maximizar la exacción de recursos de las colonias americanas y a poner en práctica, en sus versiones menos radicales, algunos de los postulados de la Ilustración (Lynch, 1987: 7-48; Halperin Donghi, 1985: 37-74; Dym y Belaubre, 2007: 1-15). La nueva política de la Corona en la esfera educativa se expresó en el énfasis por abrir escuelas elementales. El proceso culminó durante los reinados de Fernando VI (1746-1759) y Carlos III (1759-1788), cuando se aprobó un plan de instrucción pública que dispuso enseñanza separada para niños y niñas, algunos contenidos de carácter secular y exámenes para quienes aspiraban a impartir clases, los cuales serían vigilados por funcionarios de los ayuntamientos (González Flores, 1978: 45-46; Herrera, 2007: 21-25).

Las Reformas Borbónicas coincidieron, en el caso costarricense, con la primera fase de la colonización campesina del oeste del Valle Central, la cual tuvo dos efectos importantes en cuanto a la educación: limitó la población en edad escolar de Cartago, el

Cuadro 1. Maestros contratados para atender escuelas elementales según lugar y periodo (datos fragmentarios). Costa Rica (1583-1811)

\begin{tabular}{|c|c|c|c|c|c|}
\hline Lugar & $1583 / 1588-1699$ & $1700-1749$ & $1750-1799$ & $1800-1811$ & Total \\
\hline Cartago & 1 & 7 & 6 & 5 & 20 \\
\hline Heredia & & & 3 & & 3 \\
\hline San José & & & 2 & 2 & 3 \\
\hline Alajuela & & & & 1 & 1 \\
\hline Esparza & & & 1 & 1 & 2 \\
\hline Nicoya & & & 1 & & 1 \\
\hline Total de maestros ${ }^{\star}$ & 1 & 7 & 13 & 9 & 30 \\
\hline $\begin{array}{l}\text { Escuelas públicas } \\
\text { nuevas por periodo }\end{array}$ & 1 & & 5 & 1 & 7 \\
\hline
\end{tabular}

${ }^{*}$ El número de personas quizá fue menor a 30, dado que algunos maestros pudieron ser nombrados más de una vez, pero esto no es posible determinarlo porque se desconoce el nombre de algunos de esos docentes.

Fuente: González Flores (1978: 40-51) 
espacio más "urbanizado" y de más antigua ocupación, y evitó, dada la dispersión inicial de los emigrantes, que en las áreas ocupadas por éstos se configurara, en lo inmediato, una fuerte presión por más escuelas. De esta manera, el mismo proceso que consolidó el peso económico y social de los pequeños y medianos productores agrícolas debilitó, dada su dinámica ruralizadora, el impacto del alza demográfica sobre la demanda educativa.

La dispersión de los colonos, en un contexto de crecimiento económico, condujo a las autoridades civiles y eclesiásticas, después de 1750, a emprender esfuerzos - mediante la quema de casas y cosechas y amenazas de excomunión - para concentrarlos en aldeas, con el fin de que pudieran cumplir mejor con sus deberes religiosos y fiscales (Fonseca, 1983: 165222, 287-311). La aplicación de esta política borbónica fue el contexto en que empezaron a abrirse nuevas escuelas en el este del Valle Central -barrio de La Puebla, en Cartago-, en el oeste - en los centros de San José, Heredia y Alajuela- y en comunidades distantes - Esparza y Nicoya-. Antes de la Constitución de Cádiz, el número máximo de escuelas públicas abiertas simultáneamente fue, como mínimo, de siete establecimientos. Tal expansión escolar implicó una carga económica adicional para las familias campesinas, ya que la asistencia de los niños a la escuela suponía una disminución de la fuerza de trabajo disponible, a lo que podía agregarse -en especial en el caso de los agricultores acomodados- el pago de una suma fija mensual al maestro.

Hay evidencia de que la compulsión escolar, cuyo propósito era obligar a los padres a enviar a sus hijos a la escuela, empezó a practicarse en Cartago en la década de 1710, si bien parece haberse intensificado sólo a partir del decenio de 1790 (González Flores, 1978: 42, 45, 48-49, 51). La oposición de familias campesinas a colaborar con las iniciativas escolares de las autoridades, en vez de ser interpretada como resultado de una supuesta ignorancia popular (Quesada, 2007: 143-144), debería considerarse como una respuesta al costo que implicaba acatar tales disposiciones. La actitud de esos pequeños y medianos productores agrícolas, que se resistieron a asentarse en aldeas entre 1750 y 1780 , expresaba a nivel local el descontento americano con la política expoliativa de los Borbones, cuya estrategia de fortalecer a España a costa de sus colonias culminó, al empezar el siglo XIX, en las guerras de independencia (Lynch, 1980: 9-47; Halperin Donghi: 1985: 115-186; Chiaramonte, 2003: 85-113).

El resultado quizá más interesante de este proceso fue una cierta democratización del acceso a la enseñanza, en términos sociales y étnicos. El cabildo de Cartago, desde inicios del siglo XVIII, se preocupó por que en las escuelas abiertas y financiadas con fondos municipales y aportes de los pudientes se dispusiera de una cuota mínima - entre cuatro y 12 niños- para alumnos procedentes de familias blancas empobrecidas. La política escolar impulsada en el periodo posterior a 1750 supuso ampliar el acceso a los pobres, que eran exceptuados de todo pago y podían ser dotados gratuitamente de libros de texto y de otros útiles (González Flores, 1978: 41-51), un fenómeno que no fue desconocido en otras áreas de Hispanoamérica, como fue el caso de Guanajuato en México (Thompson, 1994: 19-36). La escuela de La Puebla, por ejemplo, fue abierta en 1788 en un barrio de Cartago habitado por mulatos, negros libres y mestizos pobres (González Flores, 1978: 44; Cáceres, 2000: 91-97).

La inestabilidad de las escuelas abiertas en el este y oeste del Valle Central, generalmente motivada por la falta de pago a los maestros, tendió a disminuir en el periodo posterior a 1790, cuando se incrementó el interés de los sectores más acomodados por la educación. El creciente excedente agropecuario, proporcionado por el cultivo de tierras vírgenes, convirtió al occidente del valle en el área económica y demográficamente más dinámica de la provincia. Este proceso fue liderado por San José, que fue el eje del cultivo del tabaco, el principal producto de exportación de Costa Rica a finales del siglo xviII y asiento de la factoría respectiva (Acuña, 1978: 279-392). Las principales familias josefinas, ya en 1797, contrataron al notable cartaginés José Santos Lombardo para 
que impartiera clases de primeras letras a sus hijos. En 1803, disponían de una cátedra de gramática latina y en 1807 contaban con una escuela pública y, por lo menos, con otra privada (González Flores, 1978: 50-51, 79).

A diferencia de San Salvador y Sonsonate, donde la posición de maestro estuvo dominada por el clero - un predominio quizá asociado con el mayor peso de la población indígena- (Herrera, 2007: 21-23), en Costa Rica, desde inicios del siglo xvin, hubo una tendencia a la secularización. De 18 maestros que se desempeñaron entre 1714 y 1797 y cuya condición se conoce, sólo tres eran eclesiásticos (González Flores, 1978: 41-50). ${ }^{1}$ El análisis del salario de estos docentes es difícil porque tenía dos componentes: una suma fija al año, pagada por el cabildo de Cartago por la atención de los niños pobres, y las contribuciones que debían pagar los padres de familia. Este último ingreso, que al parecer era el principal componente del salario, dependía del número de estudiantes y del tipo de enseñanza que se les proporcionaba y, como éstos no se conocen, no hay forma de determinarlo.

No obstante lo anterior, es posible realizar un cálculo aproximado. Entre inicios y mediados del siglo XVIII, el cabildo cartaginés aportaba 25 pesos de cacao al año (unos 16.6 pesos de plata), suma que ascendió a comienzos del siglo xIX primero a $50 \mathrm{y}$ luego a 100 pesos de cacao (33.3 y 66.6 pesos de plata, respectivamente). Ahora bien, durante la mayor parte del siglo XviII las contribuciones que debían pagar los padres de familia se ajustaron a la siguiente tarifa mensual en moneda de plata: dos reales por enseñar a leer en cartilla — silabario-, cuatro reales por hacerlo en catón - libro de lectura-, seis reales por realizar esa tarea en carta y ocho reales - un peso- por enseñar a escribir y a contar. En las tres últimas categorías indicadas, la tarifa mensual bajó aproximadamente $50 \%$ a principios del siglo XIX (González Flores, 1978: 41-45, 48-51, 82).

\footnotetext{
${ }^{1}$ El número de eclesiásticos pudo haber sido ligeramente mayor (Cruz, 2003: 5).
}

Los cambios indicados parecen corresponder con una situación en la cual se pasó de una época en que la matrícula escolar era pequeña y estaba dominada por estudiantes que procedían de familias pudientes, a otra en la que se incrementó el total de alumnos, en buena medida como resultado de una mayor presencia de niños y niñas provenientes de hogares que disponían de recursos más modestos. Esta modificación cuantitativa y cualitativa en la matrícula explicaría que el aporte del cabildo aumentara, al mismo tiempo que disminuía la suma pagada por los padres. No parece, sin embargo, que esta alza en lo aportado por el cabildo compensara la baja en las contribuciones de los padres.

En efecto, la información disponible sugiere algún deterioro en el salario de los maestros a medida que la demanda escolar se expandía. A finales del siglo XVIII, el ingreso mensual de un maestro podía oscilar entre 10 y 20 pesos de plata, suma que superaba el salario de un peón agrícola - de dos a seis pesos de plata por mes-, pero que estaba por debajo de lo que devengaba el administrador de la Factoría de Tabacos en 1779 - unos 80 pesos de plata mensuales - y era igual o ligeramente inferior a los sueldos ganados por los guardas de tal institución: entre 16 y 30 pesos de plata por mes (González Flores, 1978: 44: Gudmundson, 1978: 100-101; Fallas, 1972: 50, 53, 65). En contraste, los salarios mensuales de los maestros, durante la década de 1810 e inicios de la de 1820, oscilaron entre dos y ocho pesos de plata mensuales (González Flores, 1978: 82-84, 89 y 178; Quesada, 2007: 142, 162, 167).

El ingreso de los maestros fue afectado por un cambio en la política escolar. Durante el siglo xvin e inicios del XIX, una vez abierta una escuela, se prohibía la apertura de otras que pudieran afectar su matrícula $y$, por tanto, los ingresos del maestro procedentes de las contribuciones de los padres acomodados. Ya en 1807, sin embargo, el gobernador Tomás de Acosta (1796-1810) defendía el derecho de los establecimientos particulares a competir con los públicos con base en la libertad que tenían los padres de escoger la escuela a que deseaban enviar a sus hijos 


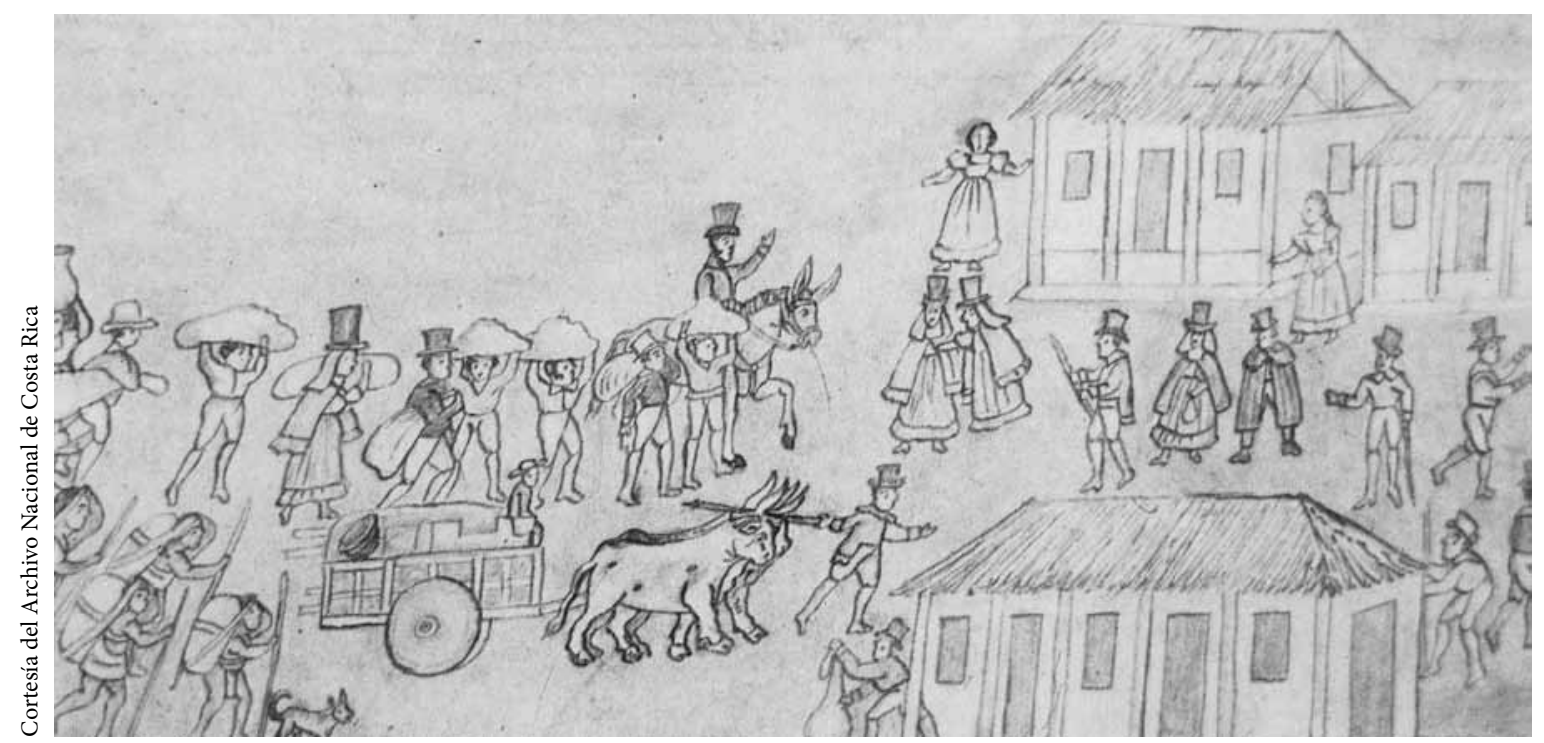

Los comienzos de San José en el siglo xviII, "Álbum de Figueroa".

(González Flores, 1978: 42-44, 48, 51), términos que evocan los empleados, con el mismo propósito, en el Buenos Aires de 1820 (Newland, 1994: 277-286).

\section{CONSTITUCIÓN DE CÁDIZ, INDEPENDENCIAY EXPANSIÓN ESCOLAR}

La política de los Borbones de ampliar el número de escuelas fue continuada por la Constitución de Cádiz (1812), la cual introdujo un cambio decisivo, al promover la expansión de ayuntamientos electivos en las distintas poblaciones y al responsabilizarlos de la apertura de establecimientos escolares (Muñoz, 2002: 8-9; Quesada, 2007: 57-58). Pese a que los datos en que se basa son fragmentarios, el cuadro 2 permite aproximarse a la expansión escolar de los años 1813-1814. Cabe advertir que la información respecto de San José, Alajuela y Cartago está bastante incompleta, aunque resalta el contraste entre las 14 escuelas reportadas y los siete establecimientos escolares que fueron abiertos entre 1750 y 1811 (véase cuadro 1). Es muy probable, además, que el total de centros de enseñanza primaria fuera superior a la cifra indicada, ya que se sabe que en los barrios de las ciudades principales se abrieron otras escuelas (González Flores, 1978: 83). Si bien se desconoce el número exacto, el total - una vez considerada la diferencia de población a favor de San José y Cartago respecto de Heredia - pudo superar fácilmente los 20 establecimientos (Cruz, 2003: 7; Dengo, 2002: 77).

No obstante que no se dispone de datos acerca de cuántos niños asistían a esas escuelas, se puede realizar una estimación conservadora de ese número mediante el siguiente procedimiento. En 1827 había un promedio nacional de 47.8 estudiantes por escuela (véase cuadro 2). De asumirse que en 1813-1814 ese promedio era de 25 alumnos y que estaban abiertas como mínimo 20 escuelas, el total de estudiantes habría alcanzado los 500 niños. Tal cálculo es bastante moderado, como lo sugiere el hecho de que, entre finales de 1820 e inicios de 1821, únicamente para la ciudad de Cartago y sus barrios se consignó una cifra similar de escolares (González Flores, 1978: 178).

Conviene comparar la experiencia costarricense con la de algunas de las principales ciudades latinoamericanas de esa época - cuyo total de habitantes era parecido al de Costa Rica - para apreciarla debidamente. En 1813, Santiago de Chile, en donde residían 50000 personas, disponía de apenas siete 
Cuadro 2. Costa Rica: población total y escuelas establecidas entre 1813 y 1814 (datos fragmentarios)

\begin{tabular}{lccc}
\hline & Lugar $^{*}$ & Población estimada \\
San José & 16497 & 31.6 & Escuelas reportadas \\
\hline Alajuela & 6787 & 13.0 & 1 \\
\hline Cartago & 12530 & 24.0 & 1 \\
\hline Heredia & 10337 & 19.8 & 8 \\
\hline Guanacaste & 4699 & 9.0 & 2 \\
\hline Puntarenas & 1358 & 2.6 & 1 \\
\hline Limón & 52208 & 100.0 & 14 \\
\hline Total & & & 2 \\
\hline
\end{tabular}

*Para facilitar la comparación con periodos posteriores se utiliza la actual división administrativa del país. Se excluye la población indígena no reducida: 800 individuos en Alajuela y 2745 en Limón y Bocas del Toro (esta última pertenecía a Costa Rica en esa época, luego fue apropiada por Colombia).

**La estimación se basa en los datos del censo de 1824 según Bernardo A. Thiel.

Fuente: González Flores (1978: 82-84); Thiel (1977: 27); Pérez (1978: 29-30; 1988: 4, 6).

establecimientos, los cuales atendían a 664 alumnos (Labarca, 1939: 75; Soto, 2000: 21). En ese mismo año, la ciudad mexicana de Guanajuato y sus suburbios, con una población de entre 60000 y 70000 personas, contaba con seis escuelas y 500 escolares de ambos sexos (Thompson, 1993: 433; 1994: 20-21, 28; Serrano, 2001: 129). En 1815, Buenos Aires, con 51779 habitantes (Frías y Méndez, 1974: 3), tenía 13 planteles elementales en los que se preparaban 1200 estudiantes (Szuchman, 1990: 132). ${ }^{2}$

De esta manera, la proporción de escolares respecto de la población total era de $1.3 \%$ en Santiago, de $2.3 \%$ en Buenos Aires, de entre 0.7 y $0.8 \%$ en Guanajuato y de $0.9 \%$ en Costa Rica. Aunque las cifras costarricenses no permiten diferenciar espacios urbanos y rurales, la comparación es significativa porque Costa Rica, en esa época, disponía de mucho menos recursos que las ciudades indicadas. Además, el cálculo es afectado a la baja porque no excluye los

\footnotetext{
${ }^{2}$ El número de escuelas en Buenos Aires pudo ser mayor, según la información aportada por Newland (1994: 277-286); el cálculo para Guanajuato es afectado por los procesos migratorios, relacionados con la actividad minera y por la guerra de Independencia.
}

datos de las áreas rurales, en las cuales la cobertura escolar era más reducida. Con base en el resultado de esta comparación, se hace necesario revisar el enfoque de algunos investigadores que, al enfatizar en las limitaciones (Quesada, 2007: 137-144: Fischel, 1987: 60-61), dejan de lado los logros educativos alcanzados en el contexto de la experiencia gaditana.

Aunque la Constitución fue abolida en $1814-\mathrm{y}$ restaurada en 1820 - la expansión escolar no parece haber sido interrumpida y fue claramente reforzada por la independencia de España, acaecida en 1821. El nuevo orden institucional consolidó el papel de los municipios como responsables de la educación (Muñoz, 2002: 57-73). Como se observa en el cuadro 3, en 1827 había ya 54 escuelas y alrededor de $48 \%$ de los niños con edades entre siete y 12 años asistía a alguno de esos establecimientos. Este dato sugiere que, ya para entonces, el acceso a la instrucción tendía a extenderse a los hijos de familias campesinas y artesanas prósperas, y que una proporción, probablemente exigua, de niños provenientes de hogares pobres también lograba alguna alfabetización. 
Cuadro 3. Costa Rica: número de escuelas, estudiantes y proporción de alumnos en relación con la población en edad escolar (PEE): 1827-1883

\begin{tabular}{|c|c|c|c|c|c|c|c|c|c|}
\hline Año & $\begin{array}{l}\text { Escuelas } \\
\text { de niños }\end{array}$ & Alumnos & $\begin{array}{l}\text { Proporción } \\
\text { de la PEE } \\
\text { masculina }\end{array}$ & $\begin{array}{l}\text { Escuelas } \\
\text { de niñas }\end{array}$ & Alumnas & $\begin{array}{c}\text { Proporción } \\
\text { de la PEE } \\
\text { femenina }\end{array}$ & $\begin{array}{l}\text { Total de } \\
\text { escuelas }\end{array}$ & $\begin{array}{l}\text { Total de } \\
\text { alumnos }\end{array}$ & $\begin{array}{c}\text { Proporción } \\
\text { de la PEE } \\
\text { total }^{*}\end{array}$ \\
\hline $1827^{\star \star}$ & 54 & 2509 & 47.6 & & & & 50 & 2509 & 24.2 \\
\hline 1834 & 41 & 2025 & 34.2 & & & & 41 & 2025 & 17.4 \\
\hline 1838 & 58 & 2415 & 38.2 & & & & 58 & 2415 & 19.4 \\
\hline 1848 & 59 & & & 2 & & & 61 & & \\
\hline 1849 & 52 & 1913 & 24.4 & 1 & 24 & 0,4 & 53 & 1937 & 12.5 \\
\hline 1851 & 62 & 3542 & 43.7 & 3 & 96 & 1,4 & 65 & 3638 & 22.8 \\
\hline $1857^{\star * *}$ & & & & & & & 42 & 2186 & 12.4 \\
\hline 1858 & & & & & & & 74 & 3851 & 21.5 \\
\hline 1859 & & & & & & & 66 & 4900 & 26.9 \\
\hline 1861 & & & & & & & 63 & 8000 & 42.4 \\
\hline 1862 & & & & & & & 75 & 8500 & 44.3 \\
\hline 1864 & & & & & & & & 6963 & 36.2 \\
\hline $1872^{* * *}$ & 59 & 3414 & 30.1 & 19 & 988 & 9,0 & 78 & 4402 & 19.7 \\
\hline $1873^{\star * *}$ & 72 & 4733 & 40.9 & 20 & 1242 & 11,1 & 92 & 5975 & 26.2 \\
\hline 1874 & & & & & & & 88 & 5446 & 21.8 \\
\hline $1876^{* * *}$ & & & & & & & 123 & 8930 & 37.0 \\
\hline 1883 & 127 & 7045 & 44.2 & 107 & 5592 & 36,3 & 234 & 12637 & 40.3 \\
\hline
\end{tabular}

${ }^{*}$ La PEE se estimó a partir de los censos de 1824, 1843-1844, 1864 y 1892. Con este fin se elaboró una serie de población total para el periodo 18271883; luego se calcularon las proporciones de la PEE, por sexo, para cada año censal, y con base en las proporciones del censo más próximo se estimó la PEE masculina y femenina para los años indicados en el presente cuadro.

**Las escuelas y estudiantes que había en Bagaces, Cañas, Esparza y Térraba, cuyos datos no están disponibles, se estimaron de la siguiente manera: un establecimiento de 30 alumnos para cada una de esas poblaciones.

***Datos incompletos.

Fuente: González Flores (1978: 180, 196, 198, 322); Muñoz (2002: 215-216); Thiel (1977: 27); Pérez (1988: 4, 6); Gudmundson (1990: 239-240); República de Costa Rica (1964: 35, 91; 1974: lviii); Meléndez (1968: 144); González Víquez (1918: 9); Cover (1982: 122); Cotton (1972: 129).

Una nueva comparación con algunas ciudades hispanoamericanas permite observar mejor los logros escolares de Costa Rica tras la emancipación de España. En 1820, la ciudad de Puebla, en México, tenía unos 52000 habitantes y contaba con 22 escuelas, a las que asistían 1711 estudiantes varones (Sánchez Albornoz, 1977: 142; Vaughan, 1987: 56), los cuales representaban alrededor de $41 \%$ de la población masculina en edad escolar, ${ }^{3}$ porcentaje infe-

\footnotetext{
${ }^{3}$ Según Vaughan, las personas en edad escolar representaban 16\% de la población total (Vaughan, 1987: 57). Con base en este porcentaje, se calculó la población total en edad escolar en 1820 y se asumió que varones y mujeres se distribuían equitativamente.
} 
rior al que había en Costa Rica en 1827. En este último año, los niños que asistían a la escuela en Costa Rica representaban 3.9\% del total de habitantes del país, una proporción similar a la de Montevideo en 1846, inferior a la de Buenos Aires en 1824 (5.9\%), a la de México en 1838 (5.7\%) y a la de Puebla en 1845 (4.5\%), y superior a la de Valparaíso en 1856 (1.9\%) (Newland, 1991b: 360).

Indudablemente importantes, esos logros costarricenses fueron también de corta duración. En vez de registrar un crecimiento acumulativo, como lo muestra el cuadro 3, la cobertura escolar mantuvo una tendencia a la baja hasta finales de la década de 1850. A partir de 1859, se inició una notable recuperación, que se prolongó durante el decenio de 1860, pero, al igual que había ocurrido antes, declinó de nuevo poco después. La explicación de estos cambios en la cobertura se relaciona, en parte, con el impacto decisivo que los intensos procesos de colonización agrícola tuvieron sobre un sistema educativo de base municipal. A medida que las familias alejaban de la infraestructura disponible, incluida la alejaban de la infraestructura disponible, incluida la destinada a la enseñanza. Puesto que la extensión de los servicios públicos - en particular, los municipales- iba a la zaga de la ocupación de nuevas tierras, una proporción creciente de niños quedó al margen del sistema educativo (Molina y Palmer, 2004: 179). De esta forma, la existencia de una frontera agrícola abierta y accesible a la población campesina, que tan fundamental fue para que Costa Rica conservara una estructura social no polarizada y con fuerte presencia de pequeños y medianos productores (Samper, 1990; Hilje, 1991), dificultó enormemente la alfabetización popular.

En parte, las alzas y bajas en la cobertura también estuvieron vinculadas con una serie de reformas institucionales que, en la mayor parte del periodo comprendido entre 1847 y 1876, redujeron los gobiernos locales a los cantones centrales de cada provincia. Al concentrar estas municipalidades la mayor parte de sus recursos en atender las demandas de los vecinos asentados en las áreas urbanas y

sus contornos inmediatos - quienes eran, también, los más influyentes políticamente-, las comunidades ubicadas en lugares distantes tendieron a ser dejadas de lado. De esta manera, las familias rurales en general, y no únicamente las pobres, se vieron perjudicadas por este proceso. Fue sólo a mediados de la década de 1870 que fueron restablecidos los municipios en todos los cantones (Araya y Albarracín, 1986: 52, 69). Dicho cambio se aprecia en los datos de 1876 y sobre todo en los de 1883 (véase cuadro 3), que muestran una clara expansión en el número de escuelas para ambos sexos y un alza importante en la proporción de niños y niñas en edad escolar que asistía a las aulas.

Finalmente, la inestabilidad en la cobertura escolar parece haber estado relacionada, además, con el hecho de que la inversión educativa no logró seguir el ritmo del crecimiento demográfico. Entre 1827 y 1851, mientras el total de habitantes incrementó en $53.8 \%$, el número de escuelas de niños apenas aumentó en $14.8 \%$, y el total de alumnos se elevó en $41.2 \%$ (véase cuadro 3). Es muy probable que el impacto del rezago indicado fuera más fuerte en los territorios recientemente colonizados. Sin embargo, alguna evidencia - que será considerada más adelante - sugiere que ni siquiera las ciudades principales ni sus áreas circundantes quedaron a salvo de este fenómeno.

En este punto, conviene hacer dos precisiones importantes. Como lo ha mostrado Antonio Viñao (1993: 159-170), la alfabetización puede expandirse con independencia del sistema escolar, dado que las personas pueden aprender a leer y a escribir en el hogar o como resultado de su inserción laboral - los aprendices en talleres y los sirvientes de ambos sexos en casas de familias acomodadas-. Para Costa Rica, no se dispone de ningún estudio en este sentido $y$, aunque es probable que algunas personas se alfabetizaran por estos medios, el avance de la alfabetización dependió fundamentalmente de la ampliación del sistema educativo.

El segundo aspecto que debe destacarse es que la educación primaria en Costa Rica, desde finales 
del siglo XVIII hasta el presente, ha sido predominantemente pública. A diferencia de algunas ciudades hispanoamericanas como Puebla, México y Buenos Aires, en las que las escuelas privadas conocieron un importante crecimiento en la primera mitad del siglo xix (Vaughan, 1990: 36; Newland, 1994: 277-286), en Costa Rica, pese al descenso de la cobertura, no hubo un desarrollo significativo de este tipo. Si bien los datos al respecto son fragmentarios, se puede anotar que la primaria privada parece haber alcanzado su mayor expansión a mediados de la década de 1870, cuando entre $14 \%$ y $16 \%$ de todas las escuelas eran particulares. La mayoría de ellas parece haberse ubicado en áreas rurales, algunas de reciente colonización (González Flores, 1978: 322; Cruz, 2003: 26).

\section{ALCANCESY LÍMITES DE LA ALFABETIZACIÓN}

Antes de analizar los resultados de la metodología empleada, es necesario aclarar algunas particularidades de las fuentes que se consultaron. La base de datos fue elaborada a partir de la información referente a novios, novias y testigos que participaron en dispensas matrimoniales en el periodo 1800 1850. Puesto que estos últimos eran mayoritariamente masculinos, tal predominio explica la desproporción a favor de los varones - 79.3\%entre las 2372 personas registradas, un total mayor a las muestras utilizadas en algunos estudios similares (Althouse, 2009: 304-313). De la información extraída, un aspecto central es la capacidad de firmar que, como se ha indicado en numerosas ocasiones, no es necesariamente un indicador seguro y exacto de que la persona sepa leer y escribir. Pese a esta limitación, debe reconocerse que saber firmar o no, en una sociedad esencialmente rural, campesina y oral, constituía, por sí sola, una diferencia significativa, al suponer algún nivel de proximidad con la cultura escrita (Vincent, 1989: 16-18; 2000: 8-21; Reay, 1991: 89-129; Munck,
2004; 275-303; Pélissier y Rébaudo, 2004: 161-202; Núñez, 2005: 117-134).

Las edades constituyen otro tipo de información que presenta algunas dificultades dada la tendencia de las personas a reportar una edad aproximada en lugar de la exacta. El 45.3\% de los 1881 varones y $7.62 \%$ de las 491 mujeres bajo estudio indicaron una edad exacta, y el resto lo hicieron en múltiplos de 10. Pese a que estas proporciones son mayores a las encontradas para otras áreas del mundo colonial (Althouse, 2009: 315-316), el problema indicado introduce cierta imprecisión en el análisis de los periodos de nacimiento, por lo que, con el fin de reducir el sesgo correspondiente, se optó por realizar el estudio por décadas y no por quinquenios, bajo el supuesto de que la mayoría de quienes nacían en un decenio dado habrían alcanzado la edad escolar en el siguiente. También los datos ocupacionales son problemáticos. Se refieren casi de manera exclusiva a los varones, puesto que, si bien categorías como hacendados, labradores y jornaleros pueden ser asociadas con grupos con trasfondos sociales y económicos más precisos, otras como comerciantes, agricultores y artesanos son más ambiguas y podían incluir diferencias muy significativas, al comprender desde productores y negociantes que ocupaban apenas mano de obra familiar hasta quienes contrataban fuerza de trabajo asalariada (Palmer y Rojas, 2003: 98-102).

Por último, otra dificultad se relaciona con el tipo de fuente utilizada, ya que fue sólo en las tres décadas finales del siglo XVIII que el matrimonio tendió a generalizarse en el Valle Central (Pérez, 1981: 481-493), un proceso asociado con las políticas borbónicas para enfrentar las uniones ilícitas y el interés de las familias campesinas por legalizar la transmisión de los derechos sobre la tierra (Rodríguez, 2000: 15-30; 2007: 185-210). De esta manera, el universo de personas analizado es social y étnicamente más representativo a medida que se avanza en el periodo del estudio, ya que en los decenios iniciales la nupcialidad - particularmente en Cartago- era una práctica característica de las elites 
Cuadro 4. Costa Rica: proporción de varones (M) y mujeres (F) que sabían firmar según periodo de nacimiento y región (1730-1839)

\begin{tabular}{|c|c|c|c|c|c|c|c|c|c|c|c|c|}
\hline \multirow{2}{*}{$\begin{array}{l}\text { Periodo de } \\
\text { nacimiento }\end{array}$} & \multicolumn{6}{|c|}{ San José, Alajuela, Cartago y Heredia } & \multicolumn{6}{|c|}{ Puntarenas y Guanacaste } \\
\hline & $M$ & Firman & $\%$ & $F$ & Firman & $\%$ & $M$ & Firman & $\%$ & $F$ & Firman & $\%$ \\
\hline $1730-1749$ & 11 & 4 & 36.4 & & & & & & & & & \\
\hline $1750-1759$ & 18 & 5 & 27.8 & 2 & 0 & 0 & & & & & & \\
\hline $1760-1769$ & 55 & 11 & 20.0 & 1 & 0 & 0 & 2 & 1 & 50.0 & & & \\
\hline $1770-1779$ & 158 & 25 & 15.8 & 7 & 0 & 0 & 3 & 1 & 33.3 & 1 & 0 & 0 \\
\hline $1780-1789$ & 356 & 87 & 24.4 & 16 & 0 & 0 & 9 & 5 & 55.6 & 2 & 0 & 0 \\
\hline $1790-1799$ & 352 & 106 & 30.1 & 15 & 0 & 0 & 32 & 16 & 50.0 & & & \\
\hline 1800-1809 & 273 & 105 & 38.5 & 36 & 1 & 2.8 & 22 & 7 & 31.8 & 1 & 0 & 0 \\
\hline $1810-1819$ & 272 & 114 & 41.9 & 93 & 7 & 7.5 & 22 & 10 & 45.5 & 8 & 0 & 0 \\
\hline $1820-1829$ & 242 & 58 & 24.0 & 213 & 15 & 7.0 & 14 & 9 & 64.3 & 5 & 1 & 20.0 \\
\hline $1830-1839$ & 40 & 5 & 12.5 & 88 & 2 & 2.3 & & & & 3 & 0 & 0 \\
\hline Total & 1777 & 520 & 29.3 & 471 & 25 & 5.3 & 104 & 49 & 47.1 & 20 & 1 & 5.0 \\
\hline
\end{tabular}

Fuente: Archivo Curia Metropolitana, Dispensas Matrimoniales (1801-1850).

españolas. Fue después de 1760 que empezó a extenderse sobre todo entre mestizos y mulatos. Fuera del Valle Central, en las actuales provincias de Guanacaste y Puntarenas, donde un campesinado disperso coexistía con grandes haciendas ganaderas (Molina, 1991: 40-45), la ilegitimidad se mantuvo muy elevada, dado que el matrimonio no se generalizó (Acuña y Chavarría, 1991: 79-108).

Considerado todo lo anterior, es posible acercarse al proceso inicial de alfabetización de la sociedad costarricense ocurrido entre finales del siglo xvinI y comienzos del xIx. El cuadro 4 permite una primera aproximación en términos de género y región. En el Valle Central - a lo que entonces correspondían mayoritariamente las áreas pobladas de San José, Alajuela, Cartago y Heredia- es visible una caída en la proporción de varones que sabían firmar entre 1730 y 1779. Pese a que está basada en un número reducido de casos, tal tendencia parece expresar el impacto que tuvo la generalización del matrimonio entre sectores sociales y étnicos distintos a las elites. A medida que la práctica se extendía entre sectores sociales muy poco alfabetizados, disminuía la proporción de individuos que sabían firmar.

Un cambio en la tendencia precedente se produjo a partir de los nacidos entre 1780 y 1789, la mayoría de los cuales habría tenido su experiencia escolar en la década de 1790. Estos niños, por tanto, se habrían beneficiado del impulso que las Reformas Borbónicas dieron a la educación en esos años. El alza señalada continuó a inicios del siglo XIX, reforzada por la expansión escolar que hubo tras la aprobación de la Constitución de Cádiz (1812) y el renovado impulso a la educación que se manifestó luego de la independencia (1821). El máximo alcanzado fue de casi $42 \%$ en los nacidos entre 1810 y 1819 , cuya experiencia escolar se concentró en la década de 1820. Esta última proporción, aunque es 
inferior al porcentaje de población masculina en edad escolar que asistía a la escuela en 1827 (véase cuadro 3), supera las estimaciones realizadas con fuentes y metodología similares para otros países de Hispanoamérica entre 1888 y 1917 (Núñez, 2005: 127). Pese a sus limitaciones, esta comparación corrobora que el logro en cuanto a cobertura en esa época temprana fue significativo.

A partir de los nacidos en el decenio de 1820, que habrían ido a la escuela 10 años después, descendió en la proporción de los que sabían firmar. La baja coincide con el rezago en la inversión educativa en relación con el crecimiento demográfico y con la intensificación de los procesos de colonización agrícola que, como se ha indicado, tendieron a alejar a la población rural de la infraestructura escolar disponible. La tendencia a la disminución se acentuó entre los nacidos a partir de 1830. Estas dos últimas proporciones se ubican en el rango de los datos ofrecidos por el Censo de 1864, según el cual el porcentaje de varones de 10 años y más, asentados en las ciudades y el campo del Valle Central y con algún grado de alfabetización, ascendía a $21.5 \%$, y el de los específicamente rurales era de 14.9\% (República de Costa Rica, 1964: 8-9, 70-83).

En contraste con los varones, la proporción de mujeres que sabían firmar fue muy reducida y su acceso a algún tipo de instrucción parece haber estado relacionado no tanto con el impulso dado a la educación por las políticas borbónicas, sino con la expansión escolar asociada con la Constitución de Cádiz. ¿Su acercamiento a la cultura escrita, antes de 1812, fue por medio de la escuela, de tutores particulares - en especial las hijas de las elites- o de un pariente masculino que les brindó alguna instrucción? El tema planteado por esta pregunta requiere, sin duda, mayor investigación: según algunas fuentes, desde inicios de la década de 1800 hubo escuela para niñas en Cartago (González Flores, 1978: 48); no obstante, otras indican que los primeros establecimientos de esta índole fueron abiertos en San José en el decenio de 1840 (Obregón, 1989: 122), aunque fue sólo a partir de la década de 1850 que la educación para niñas empezó a consolidarse (Fallas y Silva, 1985: 153-159).

De acuerdo con el cuadro 4, las nacidas entre 1810 y 1819 fueron -al igual que los varones de ese grupo de edad- las que alcanzaron el mayor porcentaje de quienes sabían firmar, el cual disminuyó en las nacidas durante los periodos siguientes. El hecho de que esta reducción coincidiera con la apertura de las primeras escuelas para niñas resalta, desde otra perspectiva, el impacto que tuvieron los procesos de colonización agrícola en el retroceso de la alfabetización. El Censo de 1864 es de nuevo útil para precisar este aspecto: $10.1 \%$ de las mujeres urbanas y rurales asentadas en el Valle Central de 10 años y más tenía algún grado de alfabetización, proporción que se reducía a 5.6\% en el caso de las rurales (República de Costa Rica, 1964: 8-9, 70-83). Así, el porcentaje correspondiente para las nacidas entre 1810 y 1819 se sitúa en el rango del grado de alfabetización que tenían las mujeres en 1864, tras la primera apertura debidamente documentada de escuelas para niñas.

Los datos de Guanacaste y Puntarenas, en contraste con los del Valle Central, muestran elevados porcentajes de varones que sabían firmar, un claro indicador de que el matrimonio no se había extendido social y étnicamente y continuaba como una práctica característica de las elites. A este respecto conviene destacar que, según el Censo de 1864, las proporciones de varones y mujeres de 10 años y más y con algún grado de alfabetización eran mayores que las de algunos de sus contrapartes, urbanos y rurales, asentados en el Valle Central. La razón de esta diferencia a favor de guanacastecos y puntarenenses parece haber sido su mayor dispersión, lo que habría provocado un mayor subregistro de los sectores más pobres e iletrados, con el consiguiente aumento proporcional de los alfabetizados entre las personas que sí fueron censadas (Molina y Palmer, 2004: 177-178).

De los varones del Valle Central se conoce la ocupación de 801 ( $45.1 \%$ del total). Como se aprecia en el cuadro 5, en las categorías más claramente asociadas con las elites la capacidad de firmar estaba 
ampliamente extendida: tal era el caso de los hacendados, comerciantes y profesionales - abogados, sacerdotes y educadores-. Tal característica estaba presente también entre los funcionarios civiles y militares, aunque entre estos últimos había un cabo y un tambor que no sabían firmar. Igualmente, todos los individuos clasificados en "otros" sabían firmar, y entre ellos había dos curanderos, cuatro escribientes, un estudiante, tres músicos y un artista, ocupaciones que eran en su mayoría de índole urbana.

Lamentablemente, de la categoría vinculada con un origen más popular, la de jornaleros, no hay suficientes datos, pero los disponibles sugieren que, entre los más pobres del campo, fue limitado el impacto de la expansión escolar de finales del siglo XVIII e inicios del xIx. La experiencia de los artesanos fue muy distinta: fue el sector ocupacional de extracción trabajadora que más se benefició con la apertura de escuelas. La razón de que así fuera se explica en mucho porque se trataba de un grupo predominantemente urbano, asentado en las ciudades de mayor importancia y en las villas - donde se ubicaba la principal infraestructura educativa-, por lo que no fue afectado por los procesos de colonización agrícola ni por el rezago de la inversión escolar en relación con el aumento de la población -la baja experimentada por los nacidos entre 1820 y 1829 no es significativa, dado que se trata sólo de dos casos-.

Las dos categorías mejor representadas, agricultores y labradores, muestran tendencias ligeramente distintas. Los labradores, que pueden ser caracterizados como productores independientes que utilizaban ante todo mano de obra familiar, alcanzaron un máximo entre los nacidos en la década de 1790,

Cuadro 5. Costa Rica: porcentaje de varones del Valle Central que sabía firmar según periodo de nacimiento y ocupación (1730-1839)*

\begin{tabular}{|c|c|c|c|c|c|c|c|c|c|}
\hline $\begin{array}{l}\text { Periodo de } \\
\text { nacimiento }\end{array}$ & 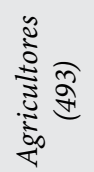 & $\frac{\substack{0 \\
\frac{1}{0} \\
\frac{0}{0}}}{\frac{0}{\sigma}}$ & 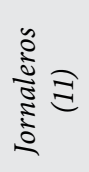 & 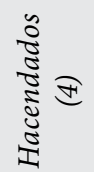 & 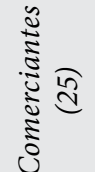 & 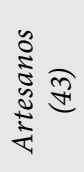 & 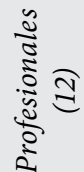 & 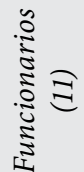 & $\begin{array}{l}\Xi \\
\Xi \\
\vdots \\
\vdots \\
0\end{array}$ \\
\hline
\end{tabular}

$1730-1749$

1750-1759

\begin{tabular}{|c|c|c|c|c|c|c|c|c|c|}
\hline $1770-1779$ & 6.3 & & & 100.0 & & 50.0 & 100.0 & & \\
\hline $1780-1789$ & 19.3 & 4.4 & & & 75.0 & 62.5 & 100.0 & & 100.0 \\
\hline $1790-1799$ & 32.4 & 28.3 & & & 75.0 & 42.9 & 100.0 & 50.0 & \\
\hline $1800-1809$ & 38.7 & 15.6 & 33.3 & & 50.0 & 50.0 & 100.0 & 100.0 & 100.0 \\
\hline $1810-1819$ & 42.4 & 20.0 & & 100.0 & 100.0 & 66.7 & 100.0 & 100.0 & 100.0 \\
\hline $1820-1829$ & 17.4 & 7.1 & & 100.0 & 100.0 & & 100.0 & 66.7 & 100.0 \\
\hline \multicolumn{10}{|l|}{$1830-1839$} \\
\hline Total & 25.8 & 15.2 & 9.1 & 100.0 & 88.0 & 48.8 & 100.0 & 81.8 & 100.0 \\
\hline
\end{tabular}

*Entre paréntesis el número total de personas.

Fuente: Archivo Curia Metropolitana, Dispensas Matrimoniales (1801-1850). 
luego experimentaron un descenso significativo en el decenio siguiente, una modesta recuperación 10 años después y, por último, una caída abrupta en los nacidos entre 1820 y 1829 . Puesto que los labradores, más que los agricultores, parecen haber liderado la colonización agrícola a finales del siglo XVIII (Samper, 1990: 81-82; 1978: 153), la trayectoria señalada sugiere que, tras beneficiarse de la mayor oferta escolar producto de las Reformas Borbónicas, la emigración hacia nuevas tierras los alejó de la más amplia infraestructura escolar surgida tras la Constitución de Cádiz. Aunque este proceso fue limitadamente contrapesado por la expansión en el número de escuelas luego de la independencia, la tendencia a la baja en la alfabetización se profundizó posteriormente, agravada por el rezago del sistema educativo respecto del crecimiento demográfico.

A diferencia de la categoría de labradores, la de agricultores es más ambigua social y económicamente, ya que se trataba de productores que podían contratar fuerza de trabajo asalariada y practicar el comercio, por lo que algunos podían pertenecer a las elites. Pese a esta limitación, los datos que ofrece el cuadro 5 presentan una tendencia creciente en la capacidad de firmar que culmina con los nacidos entre 1810 y 1819 . A partir de los nacidos en la década de 1820, que habrían alcanzado la edad escolar mayoritariamente 10 años después, hubo un descenso abrupto, que coincide con la etapa en que se intensificaron los procesos de colonización agrícola y se inició el rezago ya señalado.

En vista de la escasa información disponible para Guanacaste y Puntarenas, no se justifica realizar un análisis cronológico acerca de cómo varió la capacidad de firmar por ocupación, pero sí vale la pena conocer a qué se dedicaban los 18 varones que declararon saber firmar. De ellos, cuatro eran artesanos, tres eran jornaleros, tres eran labradores, tres eran hacendados, dos eran agricultores, dos eran comerciantes y uno era un capitán de cacería. Excepto uno de los jornaleros, las personas restantes nacieron entre 1786 y 1823 , lo que indica que se beneficiaron de la expansión educativa iniciada por las

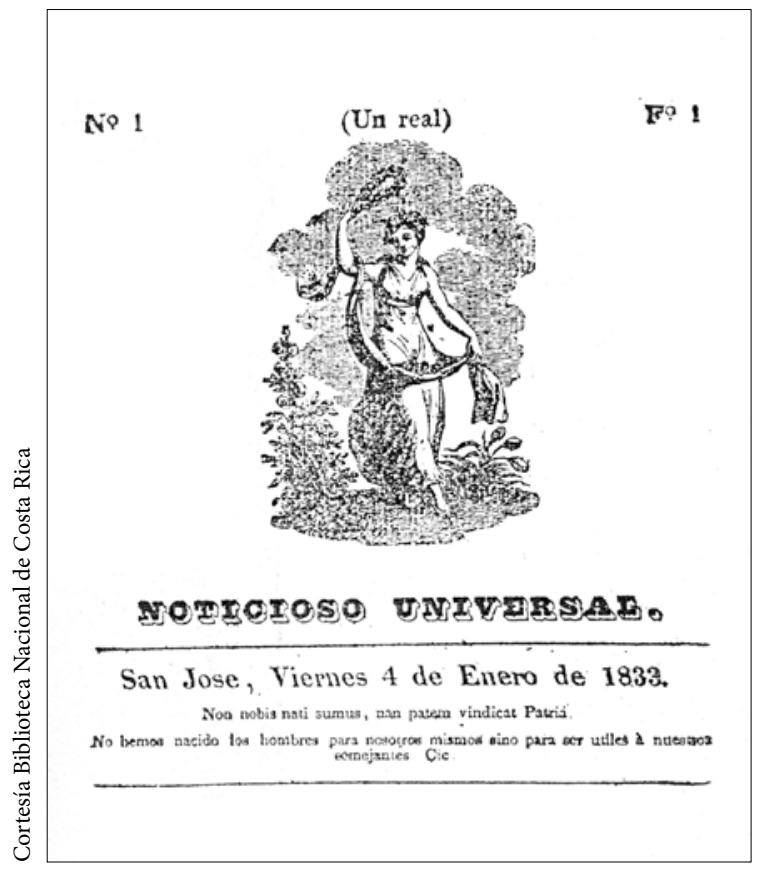

Portada del primer número del periódico Noticioso Universal.

Reformas Borbónicas, reforzada por la Constitución de Cádiz y continuada tras la independencia. Llama la atención que, en números absolutos, hubiese más jornaleros que sabían firmar en el Pacífico central y norte que en el Valle Central, diferencia que podría estar relacionada con que esa categoría tenía proporcionalmente más peso en Guanacaste y Puntarenas (República de Costa Rica, 1964: 5, 93); además, en tales áreas no hubo, en esta época, procesos de colonización agrícola que alejaran a la población de la infraestructura escolar disponible.

Con base en las fuentes consultadas, es posible diferenciar la experiencia de los varones del Valle Central residentes en las villas, o poblados menores, de la correspondiente al resto de la población masculina. Esta última comprendía una proporción considerable de los individuos avecindados en las ciudades principales y en sus entornos rurales inmediatos. Pese a que no es posible precisar más el problema, debido a la falta de datos adecuados, el cuadro 6 permite comparar el caso de quienes resultaron 
Cuadro 6. Costa Rica: porcentaje de varones del Valle Central que sabía firmar según periodo de nacimiento y lugar (1730-1839)

\begin{tabular}{|c|c|c|c|c|c|c|}
\hline \multirow{2}{*}{$\begin{array}{l}\text { Periodo de } \\
\text { nacimiento }\end{array}$} & \multicolumn{3}{|c|}{ Varones residentes en las villas } & \multicolumn{3}{|c|}{ Resto de población masculina } \\
\hline & $\begin{array}{l}\text { Total de } \\
\text { varones }\end{array}$ & Firman & Porcentaje & $\begin{array}{l}\text { Total de } \\
\text { varones }\end{array}$ & Firman & Porcentaje \\
\hline $1730-1749$ & & & & 11 & 4 & 36.4 \\
\hline $1750-1759$ & 2 & 0 & 0 & 16 & 5 & 31.3 \\
\hline $1760-1769$ & 6 & 1 & 16.7 & 49 & 10 & 20.4 \\
\hline $1770-1779$ & 12 & 2 & 16.7 & 146 & 23 & 15.8 \\
\hline $1780-1789$ & 37 & 7 & 18.9 & 319 & 80 & 25.1 \\
\hline $1790-1799$ & 38 & 6 & 15.8 & 314 & 100 & 31.9 \\
\hline $1800-1809$ & 39 & 12 & 30.8 & 234 & 93 & 39.7 \\
\hline $1810-1819$ & 30 & 9 & 30.0 & 242 & 105 & 43.4 \\
\hline $1820-1829$ & 42 & 8 & 19.1 & 200 & 50 & 25.0 \\
\hline $1830-1839$ & 6 & 1 & 16.7 & 34 & 4 & 11.8 \\
\hline Total & 212 & 46 & 21.7 & 1565 & 474 & 30.3 \\
\hline
\end{tabular}

Fuente: Archivo Curia Metropolitana, Dispensas Matrimoniales (1801-1850).

más favorecidos con la creación de infraestructura escolar desde finales del siglo XviII y quienes se beneficiaron menos. De esta comparación se puede concluir lo siguiente.

Como se ha indicado, la disminución en la cobertura escolar que se aprecia en el cuadro 3, confirmada por el descenso en la proporción de personas que sabían firmar nacidas a partir del decenio de 1820, no estuvo relacionada sólo con el desplazamiento de familias campesinas a tierras nuevas, sino también con que el sistema escolar no logró seguirle el paso al crecimiento demográfico. Tal rezago se aprecia con claridad en el cuadro 6, según el cual del fenómeno indicado no se exceptuó el resto de la población masculina, que concentraba el grueso de las personas que por estar asentadas en las ciudades principales o en los campos circundantes fueron más beneficiadas por la apertura de escuelas. Pese a que la fuente consultada no permite diferenciar entre habitantes urbanos y rurales, es probable que estos últimos fueran los más perjudicados, a juzgar por el contraste entre los datos de agricultores y labradores por un lado y las categorías ocupacionales más urbanas por otro (véase cuadro 5).

Igualmente, el cuadro 6 permite identificar algunas diferencias significativas entre el resto de la población masculina y quienes residían en las villas. En este último caso, el aumento en la proporción de varones que sabían firmar fue más tardío y el máximo porcentaje alcanzado se ubicó a considerable distancia del logrado por el resto de la población masculina. Una vez iniciado el descenso en los nacidos en la década de 1820 , tal baja fue más pronunciada entre los vecinos de las villas. Las diferencias indicadas confirman la situación más ventajosa del resto de la población masculina, que como ya se ha 
señalado concentraba a la mayoría de aquellos que residían en las ciudades principales y en sus entornos rurales inmediatos.

Pese al retroceso experimentado por la cobertura escolar, los avances logrados por la alfabetización entre finales del siglo XVIII e inicios del xIx, especialmente en las ciudades principales, sentaron la base para que, entre 1830 y 1850, la cultura impresa conociera una primera expansión. En el curso de este proceso, que tuvo por eje el casco urbano de San José, se establecieron cuatro talleres de impresión - uno del Estado-, circuló casi una veintena de periódicos, más de cien libros y folletos fueron publicados y se incrementó y diversificó la importación de libros (Meléndez, 1990: 41-84; Molina, 1995: 47-74). El deseo que documentara Hale en 1825 había dado paso a una nueva actividad económica y cultural que, en un futuro próximo, sería el eje de una incipiente esfera pública.

\section{CONCLUSIONES}

Entre finales del siglo XVIII e inicios del XIX Costa Rica experimentó una primera expansión escolar, la cual fue impulsada primero por las Reformas Borbónicas, luego por la Constitución de Cádiz y finalmente por el régimen político que surgió después de la independencia de España. Este proceso permitió que el acceso a algún nivel de instrucción se extendiera en términos sociales, étnicos y de género. Los principales beneficiarios de esta ampliación parecen haber sido los hijos de familias de pequeños y medianos productores urbanos y rurales, o en categorías ocupacionales, agricultores, labradores y artesanos. El impacto entre las mujeres y los sectores más humildes - los jornaleros - fue mucho más limitado.

En contraste con Estados Unidos, donde el periodo 1825-1850 fue clave en la expansión de la cobertura escolar (Mariscal y Sokoloff, 2000: 166-167), en Costa Rica esa cobertura, tras alcanzar un alza importante en 1827 , tendió a disminuir a partir de la década de 1830. Esto último fue resultado de tres

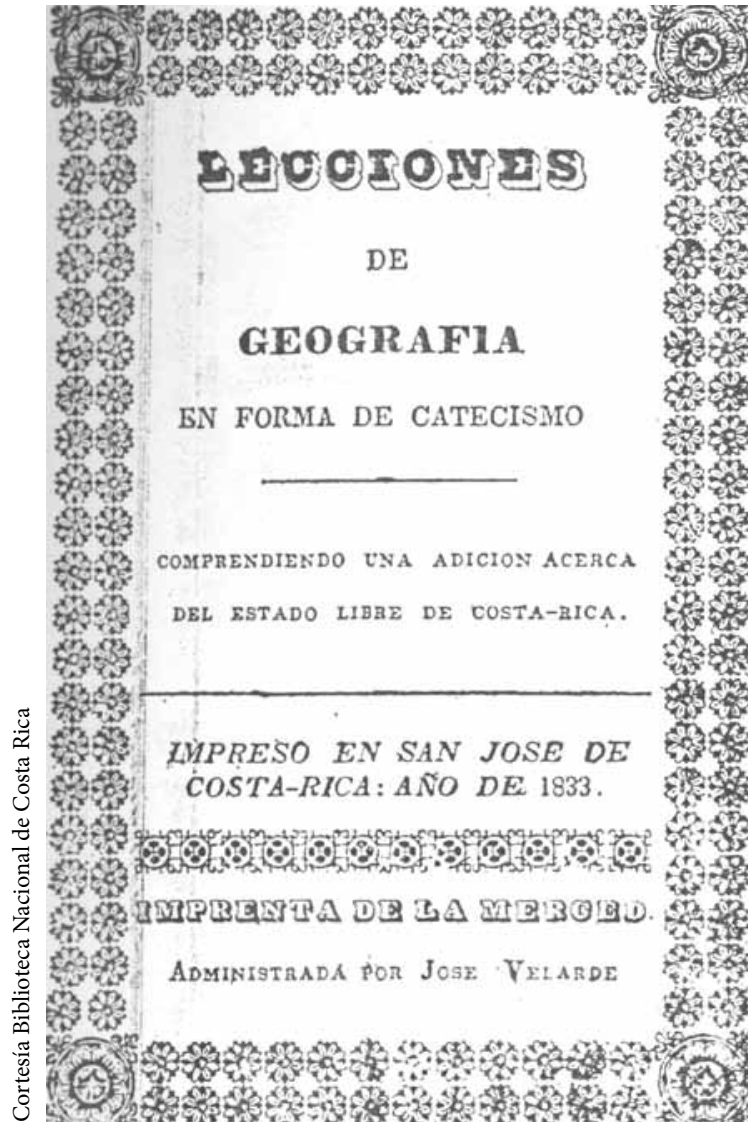

Portada de uno de los primeros libros impresos en Costa Rica, 1833

factores principales: ante todo, los intensos procesos de colonización agrícola, llevados a cabo por los campesinos, tendieron a alejar a los inmigrantes de la infraestructura escolar existente. Segundo, la inversión en infraestructura, personal y materiales educativos no siguió el ritmo del crecimiento demográfico, lo que generó una brecha cada vez mayor entre las demandas educativas y los servicios correspondientes. Y por último, la tendencia a reducir los gobiernos locales - responsables de la educación-a los cantones centrales de cada provincia, que prevaleció entre 1847 y 1876, jugó en contra de las oportunidades educativas de los hijos e hijas de las familias establecidas en áreas de reciente poblamiento.

De esta forma, después de lograr una importante cobertura a finales del decenio de 1820, el sistema 
educativo costarricense registró retrocesos importantes durante casi medio siglo. Fue sólo a partir de mediados de la década de 1870 que una combinación de mayores recursos financieros aportados por el gobierno central y el restablecimiento de municipalidades en todos los cantones permitió un aumento sostenido en la cobertura. Esta nueva expansión sentó la base para la reforma de 1886, la cual, aparte de centralizar y secularizar la educación, se caracterizó por una decisiva y vertiginosa equiparación de género, que redujo la brecha entre la alfabetización femenina y la masculina (Molina y Palmer, 2004: 186-198). Una comparación con las experiencias escolares de otras ciudades hispanoamericanas evidencia que, pese a sus limitaciones y a los retrocesos posteriores en la cobertura, la expansión educativa ocurrida en Costa Rica entre finales del siglo xVIII e inicios del xIx fue más significativa de lo que algunos investigadores han considerado hasta ahora. Los avances en la alfabetización, especialmente en las ciudades y entre sectores de pequeños y medianos productores urbanos y rurales, fueron el punto de partida para que, de 1830 en adelante, empezara a tomar forma una cultura impresa cada vez más activa, que se manifestó en la creciente producción, circulación y consumo de libros, folletos y periódicos.

\section{Bibliografía}

Acuña, María de los Ángeles y Doriam Chavarría, 1991, "El mestizaje: la sociedad multirracial en la ciudad de Cartago (1738-1821)", tesis de licenciatura en historia, Universidad de Costa Rica, Costa Rica.

Acuña, Víctor Hugo, 1978, "Historia económica del tabaco en Costa Rica: época colonial", en Anuario de Estudios Centroamericanos, núm. 4, San José, pp. 279-392.

Althouse, Aaron P., 2009, "Writing by Caste, Counting the Past: Alphabetic Literacy and Age Consciousness in the Colonial Pátzcuaro Region, 1680-1750", en The Americas, vol. LXV, núm. 3, Washington, pp. 297-319. Araya Pochet, Carlos y Priscilla Albarracín, 1986, Historia del régimen municipal en Costa Rica, Editorial Universidad Estatal a Distancia, San José.
Cáceres, Rina, 2000, Negros, mulatos, esclavos y libertos en la Costa Rica del siglo XVII, Instituto Panamericano de Geografía e Historia, México.

Chiaramonte, José Carlos, 2003, "III. Modificaciones del pacto imperial", en Antonio Annino y François-Xavier Guerra (coords.), Inventando la nación. Iberoamérica siglo XIX, Fondo de Cultura Económica, México, pp. 85-113.

Cotton, Donna Lilliam, 1972, "Costa Rica and the Era of Tomas Guardia, 1870-1882", tesis de doctorado, The George Washington University, Washington, D. C.

Cover, Edgar, 1982, "Esbozo histórico de la obra de gobierno de don Tomás Guardia", tesis de licenciatura en historia, Universidad de Costa Rica, Costa Rica.

Cruz, Vladimir de la, 2003, "La educación y la cultura costarricense en el siglo xix: de las Cortes de Cádiz a las reformas educativas", en Jorge Mario Salazar (ed.), Historia de la educación costarricense, Editorial Universidad Estatal a Distancia, San José, pp. 1-71.

Dengo, María Eugenia, 2002, Educación costarricense, Editorial Universidad Estatal a Distancia, San José.

Dym, Jordana y Christophe Belaubre, 2007, "Introduction", en Jordana Dym y Christophe Belaubre (eds.), Politics, Economy, and Society in Bourbon Central America, 1759-1821, University Press of Colorado, Boulder, pp. 1-15.

Fallas, Carmen Liddy y Margarita Silva, 1985, "Surgimiento y desarrollo de la educación de la mujer en Costa Rica 1847-1886", tesis de licenciatura en historia, Universidad de Costa Rica, Costa Rica.

Fallas, Marco Antonio, 1972, La Factoría de Tabacos de Costa Rica, Editorial Costa Rica, San José.

Fischel, Astrid, 1987, Consenso y represión. Una interpretación sociopolítica de la educación costarricense, Editorial Costa Rica, San José.

Fonseca, Elizabeth, 1983, Costa Rica colonial: la tierra y el hombre, Editorial Universitaria Centroamericana, San José.

Fonseca, Elizabeth, Patricia Alvarenga y Juan Carlos Solórzano, 2001, Costa Rica en el siglo XviII, Editorial de la Universidad de Costa Rica, San José.

Frías, Susana R. y Liliana R. Méndez, 1974, Censos y padrones existentes en el Archivo General de la Nación, 17761852, Archivo General de la Nación, Buenos Aires.

González Flores, Luis Felipe, 1978, Evolución de la instrucción pública en Costa Rica, Editorial Costa Rica, San José.

González Víquez, Cleto, 1918, "Carta a don Joaquín García Monge”, en Cleto González Víquez y Pedro Pérez Zeledón, Dos próceres, Imprenta Nacional, San José, pp. 5-19. 
Graff, Harvey, J., 2003, "Introduction to Historical Studies of Literacy", en Interchange. A Quarterly Review of Education, vol. XXXIV, núm. 2-3, Dordrecht, pp. 123-131.

Gudmundson, Lowell, 1978, Estratificación socio-racial y económica de Costa Rica: 1700-1850, Editorial Universidad Estatal a Distancia, San José.

1990, Costa Rica antes del café: sociedad y economía en vísperas del boom exportador, Editorial Costa Rica, San José.

Hale, John, 1982, "Seis meses de residencia y viajes en Centroamérica, etc.", en Ricardo Fernández Guardia (ed.), Costa Rica en el siglo XIX. Antología de viajeros, Editorial Universitaria Centroamericana, San José, pp. 13-45.

Halperin Donghi, Tulio, 1985, Historia de América Latina 3. Reforma y disolución de los imperios ibéricos 17501850, Alianza, Madrid.

Hernández, Hermógenes, 1985, Costa Rica: evolución territorial y principales censos de población, Editorial Universidad Estatal a Distancia, San José.

Herrera, Sajid, 2007, "Primary Education in Bourbon San Salvador and Sonsonate, 1750-1808", en Jordana Dym y Christophe Belaubre (eds.), Politics, Economy, and Society in Bourbon Central America, 1759-1821, University Press of Colorado, Boulder, pp. 17-45.

Hilje, Brunilda, 1991, La colonización agrícola de Costa Rica (1840-1940), Editorial Universidad Estatal a Distancia, San José.

Labarca, Amanda, 1939, Historia de la enseñanza en Chile, Imprenta Universitaria, Santiago.

Lynch, John, 1980, Las revoluciones hispanoamericanas 1808-1826, Ariel, Barcelona.

_ 1987, Hispanoamérica 1750-1850. Ensayos sobre la sociedad y el Estado, Universidad Nacional de Colombia, Bogotá, pp. 7-48.

Mahoney, James, 2001, The Legacies of Liberalism. Path Dependence and Political Regimes in Central America, The John Hopkins University Press, Baltimore.

Mariscal, Elisa y Kenneth L. Sokoloff, 2000, "Schooling, Suffrage, and the Persistence of Inequality in the Americas, 1800-1945", en Stephen Haber (ed.), Political Institutions and Economic Growth in Latin America. Essays in Policy, History and Political Economy, Hoover Institution Press, Stanford, pp. 159-217.

Meléndez, Carlos, 1968, Dr. José María Montealegre: contribución al estudio de un hombre y una época poco conocida de nuestra historia, Academia de Geografía e Historia, San José.

_ 1990, "Los veinte primeros años de la imprenta en Costa Rica 1830-1849", en Revista del Archivo Nacional, vol. LIV, núm. 1-12, San José, pp. 41-84.
Mesa-Lago, Carmelo, 2002, Buscando un modelo económico en América Latina. ¿Mercado, socialista o mixto? Chile, Cuba y Costa Rica, Nueva Sociedad, Universidad Internacional de la Florida, Caracas.

Molina, Iván, 1991, Costa Rica (1800-1850). El legado colonial y la génesis del capitalismo, Editorial de la Universidad de Costa Rica, San José.

, 1995, El que quiera divertirse. Libros y sociedad en Costa Rica (1750-1821), Editorial de la Universidad de Costa Rica, Editorial Universidad Nacional (Colección Nueva Historia), San José.

Molina, Iván y Steven Palmer, 2004, "Popular Literacy in a Tropical Democracy: Costa Rica 1850-1950", en Past and Present, núm. 184, Oxford, pp. 169-207.

Munck, Thomas, 2004, "Literacy, Educational Reform and the Use of Print in Eighteenth-Century Denmark", en European History Quarterly, vol. XXXIV, núm. 3, Londres, pp. 275-303.

Muñoz, Ileana, 2002, Educación y régimen municipal en Costa Rica 1821-1882, Editorial de la Universidad de Costa Rica, San José.

Newland, Carlos, 1991a, "Spanish American Elementary Education Before Independence. Continuity and Change in a Colonial Environment", en Itinerario, vol. XV, núm. 2, Leiden, pp. 79-95.

_ 1991b, "La educación elemental en Hispanoamérica: desde la Independencia hasta la centralización de los sistemas educativos nacionales", en Hispanic American Historical Review, vol. LXXI, núm. 2, Durham, pp. 335-364. , 1994, "The Crowding Out Effect in Education: The Case of Buenos Aires in the Nineteenth Century", en Education Economics, vol. II, núm. 3, Abingdon, pp. 277-286.

Núñez, Javier, 2005, "Signed with an X: The Evolution of Literacy in Latin America and the Caribbean, 19001950", en Latin American Research Review, vol. XL, núm. 2, Austin, pp. 117-134.

Obregón, Clotilde, 1989, Carrillo: una época y un hombre 1835-1842, Editorial Costa Rica, San José.

Palmer, Steven y Gladys Rojas, 2003, "Educando a las senoritas: formación docente, movilidad social y nacimiento del feminismo en Costa Rica (1885-1925)", en Iván Molina y Steven Palmer, Educando a Costa Rica. Alfabetización popular, formación docente y género (1880-1950), Editorial Universidad Estatal a Distancia, San José, pp. 67-141.

Pan American Union, 1928, "Notable Social Welfare Institutions in Costa Rica", en Bulletin of the Pan American Union, vol. LXX, núm. 12, Washington, pp. 1228-1229. 
Pélissier, Jean Pierre y Danièle Rébaudo, 2004, “Une approche de l'illettrisme en France. La signature des actes de mariage au xixe siècle dans l'enquête 3000 familles”, en Histoire \& Mesure, vol. XIX, núm. 1-2, París, pp. 161-202.

Pérez, Héctor, 1978, "Las variables demográficas en las economías de exportación: el ejemplo del Valle Central de Costa Rica (1800-1950)", en Avances de Investigación del Proyecto de Historia Social y Económica de Costa Rica 1821-1945, núm. 7, San José, pp. 1-68.

— 1981 , "Deux siècles d'illégitimité au Costa Rica 1770-1974”, en Jacques Dupaquier, Etienne Hélin, Peter Laslett, Massimo Livi-Bacci y Solvi Sogner (eds.), Marriage and Remarriage in Populations of the Past, Academic Press, Londres, pp. 481-493.

— 1988 , "La población de Costa Rica según el obispo Thiel”, en Avances de Investigación del Centro de Investigaciones Históricas, núm. 42, San José, pp. 1-13.

Quesada, Juan Rafael, 2007, Educación y ciudadanía en Costa Rica de 1810 a 1821: del crepúsculo colonial al umbral de la modernidad política, Editorial de la Universidad de Costa Rica, San José.

Quirós, Claudia, 1990, La era de la encomienda, Editorial de la Universidad de Costa Rica, San José.

Reay, Barry, 1991, “The Context and Meaning of Popular Literacy: Some Evidence from Nineteenth-Century Rural England", en Past and Present, núm. 131, Oxford, pp. 89-129.

República de Costa Rica, 1964, 1864 Censo de población, Dirección General de Estadística y Censos, San José.

_ 1974, Censo general de la República de Costa Rica levantado bajo la administración del licenciado don José J. Rodríguez el 18 de febrero de 1892, Dirección General de Estadística y Censos, San José.

Rodríguez, Eugenia, 2000, Hijas, novias y esposas. Familia, matrimonio y violencia doméstica en el Valle Central de Costa Rica (1750-1850), Editorial Universidad Nacional, Heredia.

_ 2007, "Relaciones ilícitas y matrimonios desiguales. Bourbon Reforms and the Regulation of Sexual Mores in Eighteenth-Century Costa Rica”, en Jordana Dym y Christophe Belaubre (eds.), Politics, Economy, and Society in Bourbon Central America, 1759-1821, University Press of Colorado, Boulder, pp. 185-210.

Samper, Mario, 1978, "Los productores directos en el siglo del café", en Revista de Historia, núm. 7, Heredia, pp. 123-217.
, 1990, Generations of Settlers. Rural Households and Markets on the Costa Rican Frontier, 1850-1935, Westview Press, Boulder.

Sánchez Albornoz, Nicolás, 1977, La población de América Latina desde los tiempos precolombinos al año 2000, Alianza, Madrid.

Serrano, José Antonio, 2001, Jerarquía territorial y transición política: Guanajuato, 1790-1836, El Colegio de Michoacán, Zamora.

Soto, Fredy, 2000, Historia de la educación chilena, Centro de Perfeccionamiento, Experimentación e Investigaciones Pedagógicas, Santiago.

Szuchman, Mark D., 1990, "Childhood Education and Politics in Nineteenth-Century Argentina: The Case of Buenos Aires", en Hispanic American Historical Review, vol. LXX, núm. 1, Durham, pp. 109-138.

Thiel, Bernardo A., 1977, "Monografía de la población de la República de Costa Rica en el siglo xIx", en Población de Costa Rica y orígenes de los costarricenses, Editorial Costa Rica, San José, pp. 15-72.

Thompson, Angela T., 1993, “To Save the Children: Smallpox Inoculation, Vaccination, and Public Health in Guanajuato, Mexico, 1797-1840", en The Americas, vol. XLIX, núm. 4, Washington, pp. 431-455.

- 1994, "Schooling in Guanajuato, Mexico, 17901840", en John A. Britton (ed.), Molding the Hearts and Minds. Education, Communications, and Social Change in Latin America, Scholarly Resources Inc., Wilmington, pp. 19-36.

Vaughan, Mary Kay, 1987, "Primary Schooling in the City of Puebla, 1821-1860", en Hispanic American Historical Review, vol. LXVII, núm. 1, Durham, pp. 39-62. , 1990, "Primary Education and Literacy in Nineteenth-Century Mexico: Research Trends, 1968-1988”, en Latin American Research Review, vol. XXV, núm. 1, Albuquerque, pp. 31-66.

Vega, Patricia, 1995, De la imprenta al periódico. Los inicios de la comunicación impresa en Costa Rica 18211850, Editorial Porvenir, San José.

Vincent, David, 1989, Literacy and Popular Culture. England 1750-1914, Cambridge University Press, Cambridge.

— 2000, The Rise of Mass Literacy. Reading and Writing in Modern Europe, Polity Press, Cambridge.

Viñao, Antonio, 1993, “Alfabetización y escolarización”, en Fundación Santa María, Historia de la educación en España y América. La educación en la España moderna (siglos XVI-XVIII), Ediciones Morata, Madrid, pp. 159-170. 